Check for updates

Cite this: RSC Adv., 2017, 7, 27342

Received 12th April 2017

Accepted 17th May 2017

DOI: $10.1039 / \mathrm{c} 7 \mathrm{ra04170e}$

rsc.li/rsc-advances

\section{Imidazolium-functionalized anion exchange membranes using poly(ether sulfone)s as macrocrosslinkers for fuel cells $\uparrow$}

\author{
Xiao Ling Huang, Chen Xiao Lin, En Ning Hu, Faizal Soyekwo, Qiu Gen Zhang, (D) \\ Ai Mei Zhu and Qing Lin Liu (D)*
}

A series of novel macrocrosslinked imidazolium-based anion exchange membranes (AEMs) with high hydroxide conductivity and dimensional stability were synthesized by crosslinking a poly(vinyl imidazole) ionic liquid with bromide-terminated poly(ether sulfone) via Menshutkin reaction. Fourier transform infrared (FT-IR) and energy dispersive spectrometry (EDS) were used to confirm the chemical structure and successful crosslinking of the AEMs. The contiguous imidazolium cations along the polyolefin backbone are found to aggregate and connect to form continuous hydroxide transport microchannels by the introduction of long hydrophobic poly(ether sulfone) chain as evidenced by atomic force microscopy (AFM). As a consequence, a high hydroxide conductivity of $78.5 \mathrm{mS} \mathrm{cm}^{-1}$ was achieved for the crosslinked PES/PVIIL-0.4 membrane at $80{ }^{\circ} \mathrm{C}$. A single cell test using the PES/PVIIL-0.4 membrane exhibits an open circuit voltage of $1.039 \mathrm{~V}$ and peak power density of $109.5 \mathrm{~mW} \mathrm{~cm}{ }^{-2}$ at the current density of $190 \mathrm{~mA} \mathrm{~cm}{ }^{-2}$ at $60{ }^{\circ} \mathrm{C}$. This newly developed strategy holds great promise to prevent fuel crossover in alkaline fuel cells.

\section{Introduction}

Proton exchange membrane fuel cells (PEMFCs) have currently drawn wide attention in the new energy generation field because of their higher energy density, higher energy conversion efficiency and lower environmental pollution than traditional fossil fuels. ${ }^{\mathbf{1 - 3}}$ However, the extensive commercialization of PEMFCs still faces some critical challenges particularly emanating from the intensive dependence on precious noble metal based catalysts, sluggish fuel oxidation/oxygen reduction kinetics and the limited longterm service time of proton exchange membranes (PEMs)., ${ }^{\mathbf{4} 5}$ Furthermore, the most commonly used Nafion membranes readily suffer from issues of environmental incompatibility, excessive fuel permeation and declining proton conductivity at low relative humidity. ${ }^{6-8}$ This reduces not only the fuel use efficiency but also the open circuit potential of PEMFCs, thus lowering their overall performance. ${ }^{9}$ To overcome these

Fujian Provincial Key Laboratory of Theoretical and Computational Chemistry, Department of Chemical \& Biochemical Engineering, College of Chemistry \& Chemical Engineering, Xiamen University, Xiamen 361005, China. E-mail: qlliu@ xmu.edu.cn

$\dagger$ Electronic supplementary information (ESI) available: Preparation of the crosslinked PES/PVIIL- $x$ membranes; ${ }^{1} \mathrm{H}$ NMR spectra of (a) HO-PES-OH and (b) $\mathrm{Br}-\mathrm{PES}-\mathrm{Br}$ in $\mathrm{CDCl}_{3}$; GPC plots of HO-PES-OH and Br-PES-Br in the experiment; FT-IR spectra of the PES/PVIIL- $x$ membranes and Br-PES-Br; FT-IR spectra of the PES/PVIIL-0.4 membrane (i) before (ii) after immersing in a $2 \mathrm{M} \mathrm{KOH}$ solution at $60{ }^{\circ} \mathrm{C}$ for 30 days. See DOI: $10.1039 / \mathrm{c} 7 \mathrm{ra04170e}$ challenges, much more attention is focused on the development of anion exchange membrane fuel cells (AEMFCs) owing to their faster electrokinetics, higher catalyst resistance to carbon monoxide and wider choice of non-precious metal catalysts (e.g. $\mathrm{Ni}, \mathrm{Co}$ and $\mathrm{Ag}$ ), which significantly reduces the cost of fuel cells. ${ }^{\mathbf{1 0 - 1 4}}$

As a critical component in AEMFCs, anion exchange membranes (AEMs) play a role in separating the fuel and oxygen and simultaneously transferring hydroxide ions. Different from PEMs, the migration of hydroxide ions inside AEMs starts from the anode to cathode, and is opposite to the diffusion direction of fuel, dramatically preventing the fuel crossover of AEMs and facilitating the effective utilization of fuels. ${ }^{15}$ However, the inherent lower mobility of $\mathrm{OH}^{-}$(2.69) than $\mathrm{H}^{+}$(4.76) at room temperature (RT) in an extremely dilute solution is an impediment to improve the conductivity of AEMs to the level of PEMs. ${ }^{16}$ This makes it particularly necessary to design efficient polymer structures with high ionic exchange capacity (IEC). ${ }^{17-19}$ Paradoxically, many more hydroxide conduction groups introduced to the polymer electrolytes usually result in high water uptake, excessive membrane swelling and poor mechanical stability. ${ }^{20,21}$ This would potentially release catalyst layers from both sides of electrodes and eventually upset the fabrication of membrane electrode assembly (MEA). ${ }^{22}$

Crosslinking is used as one of the most efficient and promising methods to address this challenge. This technique can simultaneously achieve good physical properties and high 
conductivity. For example, Lee and co-workers ${ }^{23,24}$ reported the preparation of end-group crosslinked PEMs and AEMs with unusual morphological transformation using thermal alkyne trimerization. The ionic groups were found to rearrange to improve conductivity efficiency and the dimensional stability with a lower hydration number. However, the conventional crosslinked AEMs are normally prepared at the cost of consuming functional halomethyl groups for producing crosslinked structure thus reducing the content of functional ionic groups. ${ }^{25,26}$ In order to get rid of the drawbacks from the traditional crosslinked technique, the development of novel crosslinked membranes through imidazolium or quaternization reaction is becoming more attractive. ${ }^{27-30}$ For example, Wang et $a l .{ }^{31}$ reported that crosslinked poly(ether ether ketone) AEMs prepared using 1,4-diazabicyclo-2,2,2-octane as both the crosslinking and quaternization reagent achieved low swelling ratio of $48.2 \%$ at $60{ }^{\circ} \mathrm{C}$ but high conductivity of $33.4 \mathrm{mS} \mathrm{cm}^{-1}$ at $25{ }^{\circ} \mathrm{C}$. On the other hand, the development of a membrane with efficient ion conductive channels is another strategy to enhance the mechanical properties while maintaining high hydroxide conductivity because of the microphase separation morphology. The comb-shaped ${ }^{32,33}$ and block ${ }^{34,35}$ AEMs are found to favor the formation of ionic transport channels due to the aggregation of hydrophilic ionic moieties. For example, Li et al. demonstrated a series of comb-shaped $\mathrm{C}_{y} \mathrm{D}_{x}$ cationic copolymers with varied length of alkyl side chains. ${ }^{33}$ The $\mathrm{C}_{16} \mathrm{D}_{x}$ membrane with the longest hexadecyl chain achieved the highest conductivity due to its unique architecture induced by self-assembly of hydrophilic cationic groups and long hydrophobic alkyl side chains. Moreover, longer hydrophobic polymer chains between the hydrophilic pendent domains promote the gathering of hydrophobic segments. ${ }^{16}$ It is thus apparent that good molecular structural design of hydrophilic/hydrophobic microphase separation morphology tends to improve the efficiency of $\mathrm{OH}^{-}$ hopping conduction in AEMs. ${ }^{36}$

In this work, a new kind of macrocrosslinked imidazoliumbased anion exchange membranes (AEMs) was prepared via imidazolium reaction. Poly(vinyl imidazole) (PVI) was chosen as the main chain material particularly due to: (1) abundant functional sites, (2) facile synthesis, and (3) higher thermal stability than the conventional quaternary alkyl ammonium cations. ${ }^{8}$ Moreover, the inherent inadequate alkaline stability of AEMs containing imidazoliums can be effectively enhanced via crosslinking. ${ }^{27,37}$ PES is tailored-synthesized as a macrocrosslinker because of the excellent mechanical property and thermal stability. ${ }^{29}$ The dense imidazolium groups of PVIIL facilitate the aggregation of ionic exchange moieties ${ }^{5,38}$ and the Br-PES-Br with long hydrophobic chain further promotes the phase separation of hydrophilic imidazolium from hydrophobic PES. ${ }^{36}$ By varying the feeding weight ratio of $\mathrm{Br}$ PES-Br to PVIIL, a series of imidazolium-based AEMs with excellent microstructure were prepared and characterized. Furthermore, the properties of the as-synthesized membranes including hydroxide conductivity, water uptake, swelling ratio, mechanical properties and alkaline stability were investigated.

\section{Experimental section}

\section{Materials and reagents}

1-Bromobutane (98\%, Sinopharm Chemical Reagent Co., Ltd, China), bis(4-fluorophenyl)sulfone (FPS) (99\%, TCI, Japan), 4,4' (hexafluoroisopropylidene)diphenol (BPHF) (98\%, Aladdin, China), $\alpha, \alpha^{\prime}$-dibromo- $p$-xylene (98\%, TCI, Japan) were used as received. 1-Vinyl imidazole (VIm) (99.0\%, Aladdin, China) was purified via vacuum distillation. Azodiisobutyronitrile (AIBN) (99.0\%, Tianjin Guangfu Fine Chemical Research Institute, China) was recrystallized from methanol prior to use. Toluene and $N, N$-dimethylacetamide (DMAc) (99.8\%, Aladdin, China) were dehydrated by stirring over $\mathrm{CaH}_{2}$ for $24 \mathrm{~h}$ and then distilling under reduced pressure. All other reagents were available from Sinopharm Chemical Reagent Co., Ltd and used without further purification.

\section{Preparation of anion exchange membranes}

Fabrication of poly(vinyl imidazole) (PVI). The polymerization of vinyl imidazole was carried out via free radical polymerization, ${ }^{39}$ as shown in Scheme 1 . Briefly, vinyl imidazole (3.76 g, $40 \mathrm{mmol}$ ) was first dissolved in DMF $(15 \mathrm{~mL})$ under vigorous stirring, followed by the addition of AIBN ( $0.0328 \mathrm{~g}, 0.5$ $\mathrm{wt} \%$ ) as the initiator. Next, the mixture was refluxed in a $100 \mathrm{~mL}$ three-necked round bottom flask equipped with a condenser, a magnetic stirrer, a nitrogen inlet and outlet at $75{ }^{\circ} \mathrm{C}$ for $24 \mathrm{~h}$. After cooling to room temperature (RT), the product was precipitated and Soxhlet extracted with acetone for $24 \mathrm{~h}$. Finally, the resulting wet solid was dried under vacuum at $80{ }^{\circ} \mathrm{C}$ overnight to obtain an oyster white solid powder of PVI (yield: $92 \%$ ).

Preparation of poly(vinyl imidazole)ionic liquid (PVIIL). PVIIL was prepared by partial functionalization of PVI with 1bromobutane via Menshutkin reaction. ${ }^{5}$ Typically, PVI (9.41 g, $0.1 \mathrm{~mol}$ ) was dissolved in DMSO $(80 \mathrm{~mL})$ in a $250 \mathrm{~mL}$ threenecked round bottom flask equipped with a condenser, a mechanical stirrer, a nitrogen inlet and outlet. 1-Bromobutane $(9.72 \mathrm{~mL}, 0.09 \mathrm{~mol})$ was then injected as the functionalization agent. The mixture was stirred at $50{ }^{\circ} \mathrm{C}$ under a nitrogen atmosphere for $24 \mathrm{~h}$, after which it was precipitated in abundant diethyl ether to obtain viscous syrup-like PVIIL. The resultant reddish brown product was dissolved in ethanol and then recrystallized with excess ethyl acetate, vigorously stirred and filtered to remove the dissolved impurity. It was finally dried under vacuum at $25{ }^{\circ} \mathrm{C}$ to slowly vaporize the remaining diethyl ether to obtain a pure product, which was stored in a desiccator for further use.

Synthesis of HO-PES-OH and Br-PES-Br. The HO-PES-OH was made via nucleophilic substitution polycondensation according to a previous method ${ }^{40}$ as shown in Scheme 1 . With DMSO as the solvent and toluene as the azeotropic solvent, FPS (1.270 g, 5 $\mathrm{mmol}$ ), BPHF (2.016 g, $6 \mathrm{mmol})$ and anhydrous $\mathrm{K}_{2} \mathrm{CO}_{3}(1.659 \mathrm{~g}$, $12 \mathrm{mmol}$ ) were introduced into a dry $100 \mathrm{~mL}$ three-necked flask equipped with a Dean-Stark trap, a condenser, a magnetic stirrer, a nitrogen inlet and outlet. The mixture was initially heated to $140{ }^{\circ} \mathrm{C}$ and then refluxed for $4 \mathrm{~h}$ for dehydration. Then the temperature was slowly raised to $165^{\circ} \mathrm{C}$ and maintained for 


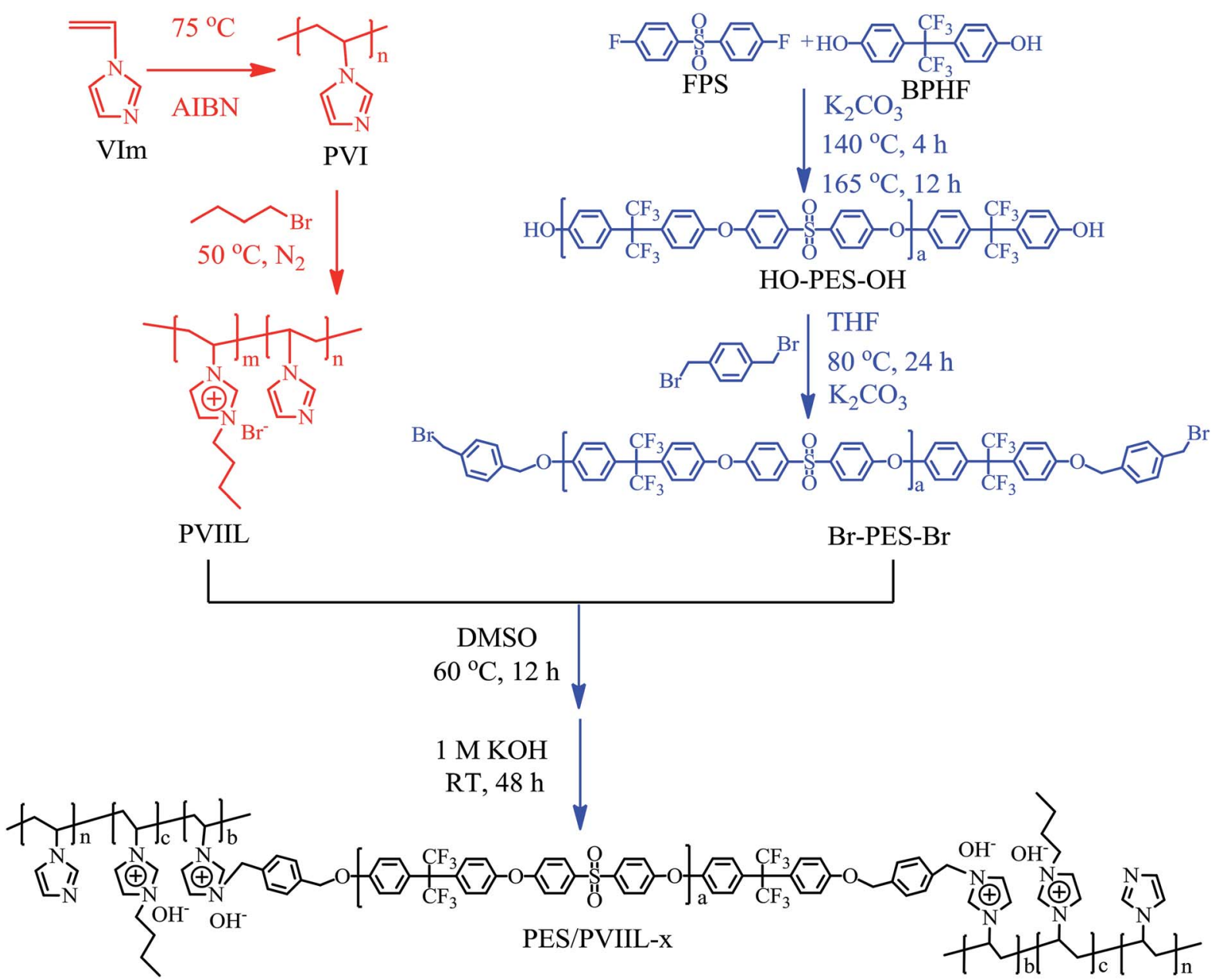

Scheme 1 Synthesis of PVIIL, Br-PES-Br and PES/PVIIL-x copolymers.

another $12 \mathrm{~h}$ to complete the copolymerization. After cooling to $\mathrm{RT}$, the resultant mixture was decanted into excess aqueous isopropanol solution under vigorous stirring (deionized water/ isopropanol $=1 / 1, \mathrm{v} / \mathrm{v}$ ) to give a precipitate. Subsequently, the precipitate was filtered out and purified by three cycles of washing with isopropanol, followed by drying under vacuum at $80{ }^{\circ} \mathrm{C}$ overnight to obtain a white solid powder of HO-PES-OH.

In order to further convert HO-PES-OH into Br-PES-Br, $\alpha, \alpha^{\prime}$ dibromo- $p$-xylene and THF were employed as the end-capping reagent and solvent respectively as illustrated in Scheme 1. Typically, HO-PES-OH $(0.926 \mathrm{~g}, 0.3 \mathrm{mmol}), \alpha, \alpha^{\prime}$-dibromo- $p$ xylene $(0.396 \mathrm{~g}, 1.5 \mathrm{mmol})$ and $\mathrm{K}_{2} \mathrm{CO}_{3}(0.417 \mathrm{~g}, 3 \mathrm{mmol})$ were simultaneously charged into THF $(30 \mathrm{~mL})$ contained in a 100 $\mathrm{mL}$ three-necked flask equipped with a condenser, a magnetic stirrer, a nitrogen inlet and outlet. The resulting mixture was heated to $80^{\circ} \mathrm{C}$ to take a reaction under a nitrogen atmosphere for $24 \mathrm{~h}$. The precipitation and purification were conducted at the same conditions as described above. Finally, the pure BrPES-Br was obtained and kept in a desiccator.

Preparation of the crosslinked PES/PVIIL- $x$ membranes. The crosslinking of PVIIL with Br-PES-Br is illustrated in Scheme 1 and the detailed steps are displayed in Scheme S1 (ESI $\dagger$ ).
Typically, a certain amount of PVIIL and Br-PES-Br was dispersed in DMSO in sequence and heated to $60^{\circ} \mathrm{C}$ for $4 \mathrm{~h}$ to ensure complete dissolution. Then both of the warm solutions were immediately mixed together to form a $5 \mathrm{wt} \%$ solution.

After vigorously stirring for $5 \mathrm{~min}$, the resulting mixture was filtered through a $0.45 \mu \mathrm{m}$ PTFE filter, poured onto a flat glass plate and then dried at $60^{\circ} \mathrm{C}$ in a vacuum oven for $24 \mathrm{~h}$ to slowly evaporate the solvent. The resultant transparent membrane is gently peeled off from the plate and treated with a $1 \mathrm{M}$ aqueous $\mathrm{KOH}$ solution at RT for $24 \mathrm{~h}$ to produce the hydroxide form membrane. Next, the membrane was repeatedly washed with deionized (DI) water for more than $48 \mathrm{~h}$ and then kept in $\mathrm{N}_{2}$ saturated DI water in a sealed container in order to avoid carbon dioxide contamination. The as-obtained crosslinked membrane is designated as PES/PVIIL- $x$, where $x$ is the feeding weight fraction of Br-PES-Br. Herein, three kinds of membranes (PES/ PVIIL-0.67, PES/PVIIL-0.5 and PES/PVIIL-0.4) were prepared.

\section{Morphology and composition characterization}

${ }^{1}$ H NMR and FT-IR spectroscopy. With the purified polymer dissolved in deuterated dimethyl sulfoxide (DMSO- $d_{6}$ ) or deuterated chloroform $\left(\mathrm{CDCl}_{3}\right),{ }^{1} \mathrm{H}$ NMR was conducted on 
Advance II 500 (Bruker, Switzerland) to confirm the successful synthesis of PVI, PVIIL, HO-PES-OH and Br-PES-Br. The FT-IR analysis of the PES/PVIIL- $x$ membranes and Br-PES-Br powder was carried out on a Nicolet Avatar 380 spectrophotometer (Thermo Electron Corporation, USA) in the range of 4000-500 $\mathrm{cm}^{-1}$ with a wavenumber resolution of $6 \mathrm{~cm}^{-1}$. Air was used for the deduction of background absorption in FT-IR.

Gel permeation chromatography (GPC) measurement. GPC measurement system (Waters, Milford, MA) equipped with three Styragel columns (Waters HT4, HT5E and HT6), a Waters 1515 isocratic HPLC pump and a Waters 2414 refractive index detector was employed to determine the molecular weight of the polymers dissolvable in tetrahydrofuran (THF). Typically, THF made especially for HPLC served as the eluent and polystyrene acted as the standard. The crosslinked membrane was insoluble in most common organic solvents at RT.

Gel fraction. Gel fraction was employed to characterize the completeness of the crosslinking reaction. The gel fraction of the membranes was measured by immersing $2 \times 3 \mathrm{~cm}^{2}$ sized membranes in a $50 \mathrm{~mL}$ vial with DMSO at $80{ }^{\circ} \mathrm{C}$ for $24 \mathrm{~h}$. The gel fraction was determined from the ratio of the initial weight to the dried weight after testing.

Scanning electron microscopy (SEM) and energy dispersive spectrometry (EDS). The surface morphology and thickness of the membranes were observed by a field emission scanning electron microscope (SEM, Zeiss Sigma, Germany) operating at $15 \mathrm{kV}$. EDS elemental mapping, which is applied to analyze the elements existing in the samples, was studied using the SEM equipped with an energy dispersion of X-ray system. Prior to test, the membrane samples were freeze-fractured in liquid nitrogen and sputtered with platinum.

Atomic force microscopy (AFM). The morphological properties of the crosslinked films were also investigated by an atomic force microscope (AFM, Bruker Co.) in a tapping mode with the relative humidity of $60 \%$ at RT. The stiffness of the tapping probe (PPP-NCHR-50, POINTPROBE-PLUS ${ }^{\circledR}$ SiliconSPM-Sensor) ranged from $10 \mathrm{~N} \mathrm{~m}^{-1}$ to $130 \mathrm{~N} \mathrm{~m}^{-1}$. The amplitude setpoint was $6 \mathrm{mV}$.

Small angle X-ray scattering (SAXS). SAXS was used to characterize the phase separation of AEMs on a SAXSess-MC2 X-ray scattering spectrometer (Anton Paar, Austria) at RT.

Ionic conductivity. The two-electrode alternating current (AC) impedance spectroscopy method was used to determine the hydroxide conductivity of the membrane samples on a Parstat 263 electrochemical workstation (Princeton Advanced Technology, USA). After immersing in $\mathrm{N}_{2}$-saturated DI water at RT for more than $48 \mathrm{~h}$, the $\mathrm{OH}^{-}$form membranes were cut into pieces $\left(1 \times 3 \mathrm{~cm}^{2}\right)$ and assembled into a $\mathrm{N}_{2}$-degassed chamber in hydrated condition for measurement. The ionic conductivity, $\sigma\left(\mathrm{S} \mathrm{cm}^{-1}\right)$ is calculated by

$$
\sigma=\frac{L}{A R}
$$

where $L$ is the distance between the two reference electrodes (cm), $A$ is the cross-sectional surface area of the membrane $\left(\mathrm{cm}^{2}\right)$ calculated from multiplying its width by thickness, and $R$ is the membrane resistance obtained from the AC impedance data $(\Omega)$.

Ionic exchange capacity (IEC). Classically, the acid-base titration method was used to determine the practical IEC of the membrane samples. Before measurement, the membranes in $\mathrm{OH}^{-}$form were dried in a vacuum oven at $80{ }^{\circ} \mathrm{C}$ for $48 \mathrm{~h}$ to evaporate any residual water. Then the dried membranes were immersed in a $0.05 \mathrm{M} \mathrm{HCl}$ solution for another $48 \mathrm{~h}$ to ensure the complete neutralization of $\mathrm{OH}^{-}$. Finally, the rest of the $\mathrm{HCl}$ solution was back-titrated with a standardized solution of $0.01 \mathrm{M} \mathrm{KOH}$ using phenolphthalein as the indicator. The IEC $\left(\mathrm{meq}^{-1}\right)$ is estimated from

$$
\mathrm{IEC}=\frac{M_{\mathrm{o}, \mathrm{HCl}}-M_{\mathrm{e}, \mathrm{HCl}}}{m_{\mathrm{d}}} \times 100 \%
$$

where $M_{\mathrm{o}, \mathrm{HCl}}$ and $M_{\mathrm{e}, \mathrm{HCl}}\left(\mathrm{mol} \mathrm{L}^{-1}\right)$ are the milliequivalents (meq) of $\mathrm{HCl}$ before and after neutralization, respectively, and $m_{\mathrm{d}}(\mathrm{g})$ is the mass of the dried membrane samples in $\mathrm{OH}^{-}$form.

Water uptake (WU) and swelling ratio (SR). The WU and SR were examined by measuring the weight and length changes of a rectangular membrane in $\mathrm{OH}^{-}$form in the dry and wet states. Prior to measurement, the $\mathrm{OH}^{-}$form membrane was dried under vacuum at $80{ }^{\circ} \mathrm{C}$ for $48 \mathrm{~h}$ until constant weight. Then, the dried membranes were soaked in $\mathrm{N}_{2}$-saturated DI water at a given temperature for $24 \mathrm{~h}$, picked out, wiped with tissue paper and measured immediately to get the required data. The water uptake and swelling ratio of the crosslinked membranes are calculated according to following equations:

$$
\begin{gathered}
\mathrm{WU}=\frac{W_{\mathrm{w}}-W_{\mathrm{d}}}{W_{\mathrm{d}}} \times 100 \% \\
\mathrm{SR}=\frac{L_{\mathrm{w}}-L_{\mathrm{d}}}{L_{\mathrm{d}}} \times 100 \%
\end{gathered}
$$

where $W_{\mathrm{w}}$ and $L_{\mathrm{w}}$ are the weight and length in plane direction of the fully hydrated membranes, respectively, and $W_{\mathrm{d}}$ and $L_{\mathrm{d}}$ are those of the dry counterpart.

Degree of crosslinking (DC). The DC of the membranes with various amounts of Br-PES-Br was determined theoretically by the feeding ratio of Br-PES-Br to PVIIL. The Mn of Br-PES-Br was used in these calculations using the relationship:

$$
\mathrm{DC}=\frac{n_{\mathrm{c}}}{n_{\mathrm{i}} / 2} \times 100 \%
$$

where $n_{\mathrm{c}}$ is the mole numbers of Br-PES-Br and $n_{\mathrm{i}}$ is the mole numbers of PVIIL.

Mechanical property. An Instron 3343 universal testing instrument was used to study the mechanical property of the fully hydrated membranes with a stretching speed of $0.2 \mathrm{~mm}$ $\mathrm{S}^{-1}$ at RT. Before test, the membrane was kept in DI water for more than one day and then cut into a dog-bone shape $(20 \times 2$ $\mathrm{mm}^{2}$ ) for measurement.

Thermal stability. A thermogravimetric analyzer (TGA, SDTQ600, USA) was used to evaluate the thermal stability of the crosslinked membranes in the temperature range of $30-800{ }^{\circ} \mathrm{C}$ under a nitrogen atmosphere. The heating rate of the measurement was $10{ }^{\circ} \mathrm{C} \min ^{-1}$. Before thermal analysis, the 
membranes were vacuum-dried at $80{ }^{\circ} \mathrm{C}$ for more than $48 \mathrm{~h}$ to a constant weight.

Alkaline stability. The alkaline stability in a $2 \mathrm{M} \mathrm{KOH}$ solution as a function of time was examined at $60{ }^{\circ} \mathrm{C}$. After alkaline treatment, the membranes were repeatedly washed with $\mathrm{N}_{2}$ saturated DI water and soaked in it for more than $48 \mathrm{~h}$ to measure the ionic conductivity.

Membrane electrode assembly (MEA) preparation and single cell performance. The performance of a single cell using the crosslinked membranes was evaluated by a $\mathrm{H}_{2} / \mathrm{O}_{2}$ fuel cell system (YD-KS20161011, DC BRUSHLESS FAN MOTOR MINEBEA Co. Ltd) at 60 and $80^{\circ} \mathrm{C}$ with an effective testing area of $2 \times$ $2 \mathrm{~cm}^{2}$. Both the fully-hydrated gases were fed at a rate of $100 \mathrm{~mL}$ $\min ^{-1}$. The MEA made up of a membrane in the middle and anode/cathode electrodes on both the sides was built as follows. The Pt/C catalyst (40 wt\% Pt, Johnson Matthey) and ionomer were initially dispersed in an aqueous ethanol solution and DMF, respectively. Both the solutions were then mixed together and magnetically stirred vigorously, and ultrasonically dispersed for $1 \mathrm{~h}$ to produce a homogenous catalyst ink. Next, an airbrush gun filled with the catalyst ink was used to uniformly spray and distribute the catalyst on a carbon paper (Toray TCP-ode electrodes) with $1.2 \mathrm{mg} \mathrm{cm}^{-2}$ loading of Pt per electrode. The membrane was subsequently sandwiched between two catalyst-coated carbon papers, hot-pressed at $5 \mathrm{MPa}$ and $50{ }^{\circ} \mathrm{C}$ for $5 \mathrm{~min}$ and assembled in a single cell for test.

\section{Results and discussion}

\section{Synthesis and structure of copolymers and PES/PVIIL-x membranes}

Preparation and characterization of PVI, PVIIL, HO-PES-OH and Br-PES-Br. Free radical polymerization was used to prepare PVI using AIBN as the initiator. The solid state of the assynthesized PVI produced from the liquid monomer preliminarily indicates a rapid increase in molecular weight during the course of polymerization. Fig. 1a shows the ${ }^{1} \mathrm{H}$ NMR spectra of PVI in the range of 0-8.5 ppm with DMSO as the deuterated reagent. The peaks between 6.6 and $7.6 \mathrm{ppm}$ are assigned to proton of the imidazole ring. ${ }^{27}$ Meanwhile, the peaks at 1.6$2.3 \mathrm{ppm}\left(\mathrm{H}_{1}\right)$ and $2.7-3.2 \mathrm{ppm}\left(\mathrm{H}_{2}\right)$ correspond to protons from the polymer backbone. This further suggests the successful conversion from vinyl imidazole to PVI.

PVIIL was made from partial functionalization of PVI with 1bromobutane. This reaction proceeded smoothly owing to the weak steric hindrance and strong nucleophilicity of the 3position nitrogen atom in the imidazole ring as well as the high reactivity of 1-bromobutane. ${ }^{5}$ Fig. 1 b shows the ${ }^{1} \mathrm{H}$ NMR spectra of the as-synthesized PVIIL in the range of 0-11 ppm with DMSO as the deuterated reagent. Compared with PVI, peaks of protons from $\mathrm{CH} / \mathrm{CH}_{2}$ groups on the PVIIL main chain shift to downfield, appearing at the chemical shift of 1.9-2.8 ppm and 3.2$3.9 \mathrm{ppm}$. The wide peak corresponding to protons from the PVI imidazole ring is divided into three peaks in the interval from 6.5 to $10.0 \mathrm{ppm}$ when it is partially functionalized into PVIIL. ${ }^{\mathbf{1 1}}$ The different chemical environments of imidazolium cations
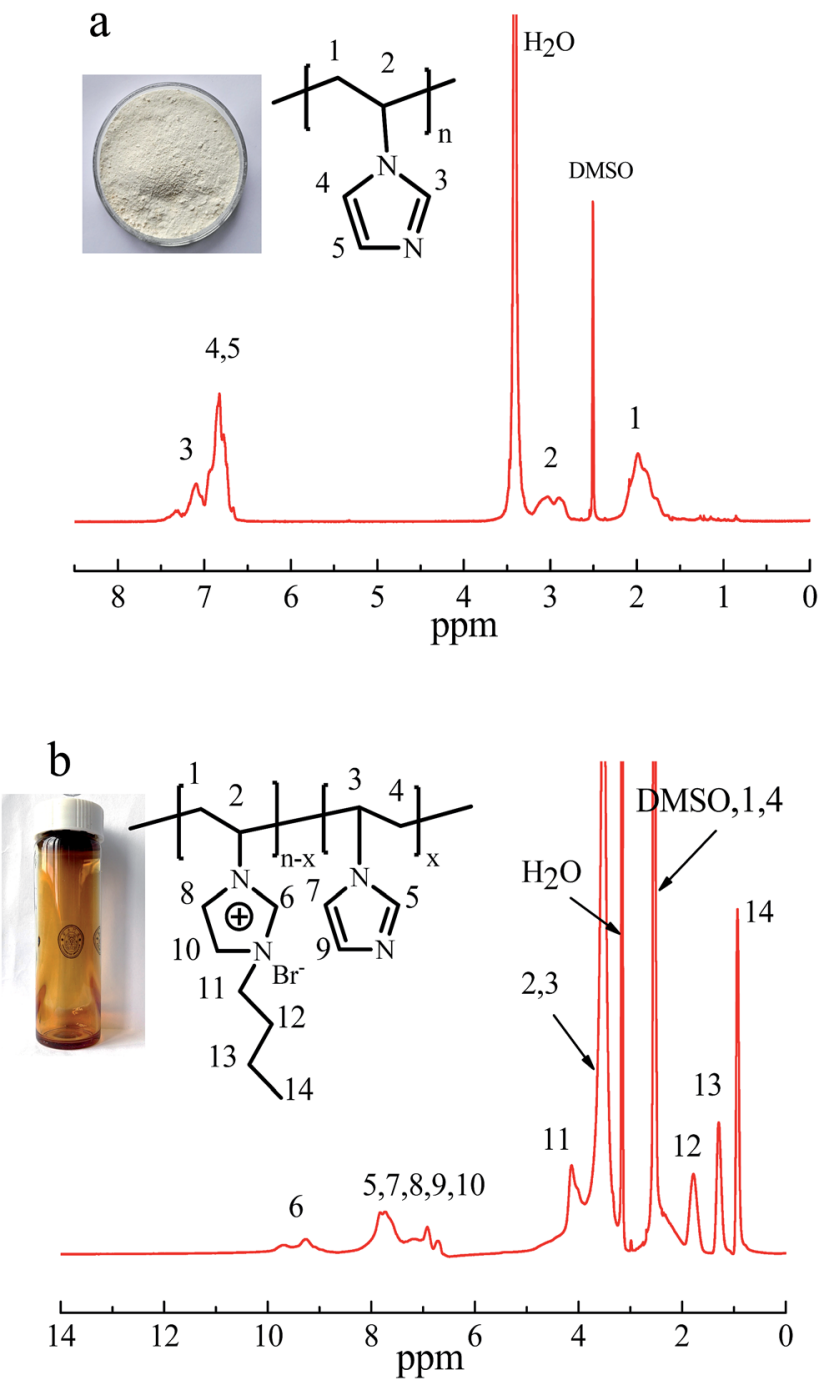

Fig. $1{ }^{1} \mathrm{H}$ NMR spectra of (a) PVI and (b) PVIIL in DMSO.

and imidazole are probably responsible for the two part peaks. The quaternization degree of PVIIL was calculated to be $68 \%$ from the integrating ratio of protons on $\mathrm{C} 2$-position of imidazolium cations $\left(\mathrm{H}_{6}\right)$ and all imidazole rings $\left(\mathrm{H}_{5}-\mathrm{H}_{10}\right)\left(\mathrm{DQ}=3 \mathrm{H}_{6} /\right.$ $\left.\mathrm{H}_{5-10}=(3 \times 1.00) / 4.42=68 \%\right)$. Overall, all of the bands at $0.6-$ $5.0 \mathrm{ppm}$ are consistent with protons in the pendant alkyl chain, ${ }^{42}$ thus suggesting the presence of 1-bromobutane in the structure.

In order to make AEMs with sufficient IEC, HO-PES-OH with predetermined molecule weight was synthesized via polycondensation reaction using $\mathrm{K}_{2} \mathrm{CO}_{3}$ as the acid-binding agent. Subsequently, Br-PES-Br was prepared from the HO-PES-OH by end-capping with excess $\alpha, \alpha^{\prime}$-dibromo- $p$-xylene. The structures of the HO-PES-OH and Br-PES-Br as recorded by ${ }^{1} \mathrm{H}$ NMR in $\mathrm{CDCl}_{3}$ are shown in Fig. S1. $\dagger$

The peaks between 6.9 and 8.1 ppm (Fig. S1a $\dagger$ ) are ascribed to protons from the benzene ring in the PES chain. ${ }^{39}$ Meanwhile, the new peaks at 4.5 and $5.1 \mathrm{ppm}$ in the ${ }^{1} \mathrm{H}$ NMR spectra of Br-PES-Br (Fig. S1b $\dagger$ ) are associated with the methylene protons in the $\mathrm{CH}_{2} \mathrm{Br}$ group from $\alpha, \alpha^{\prime}$-dibromo- $p$-xylene. This 
suggests the successful termination of HO-PES-OH. ${ }^{43}$ Furthermore, the molecular weight of HO-PES-OH and Br-PES-Br as determined by GPC is shown in Fig. S2. $\dagger$ The synthesized BrPES-Br has a higher molecular weight $\left(M_{\mathrm{n}}=9.66 \times 10^{3} \mathrm{Da}\right.$ and $\left.M_{\mathrm{w}}=13.43 \times 10^{3} \mathrm{Da}\right)$ than HO-PES-OH $M_{\mathrm{n}}=\left(7.98 \times 10^{3}\right.$ $\mathrm{Da})$ and $M_{\mathrm{w}}=\left(10.98 \times 10^{3} \mathrm{Da}\right)$ after termination. However, the increment in $M_{\mathrm{n}}$ and $M_{\mathrm{w}}$ from HO-PES-OH to Br-PES-Br is a little higher than the theoretical values $(\sim 350 \mathrm{Da})$ calculated from end-capping groups. This is mainly because a portion of Br-PES$\mathrm{Br}$ with lower molecular weight may lose during purification leading to the production of Br-PES-Br with higher molecular weight than theoretical values. Moreover, there are unavoidable errors that result from the processing of GPC data of HO-PES$\mathrm{OH} / \mathrm{Br}-\mathrm{PES}-\mathrm{Br}$ within the uncertainty of the measurements (below 10\%). ${ }^{44}$

Fabrication and characterization of the crosslinked PES/ PVIIL- $x$ membranes. The route for preparation of the crosslinked membranes based on PVIIL is illustrated in Scheme S1. $\dagger$ Owing to the strong water affinity of PVIIL, Br-PES-Br was introduced to balance the hydrophilic and hydrophobic segments of the membranes. By varying the feeding weight fraction of Br-PES-Br, three series of membranes were made.

The FT-IR spectra of the membranes and Br-PES-Br solid are shown in Fig. S3.† In comparison with Br-PES-Br, the assynthesized membranes display new strong absorption peaks at 3068,1656 and $1365 \mathrm{~cm}^{-1}$ which are attributed to the stretching vibration of $\mathrm{C}-\mathrm{H}$ and $\mathrm{C}-\mathrm{N}$ in the imidazole ring and $\mathrm{C}-\mathrm{H}$ in 1-bromobutane, respectively. ${ }^{39,45}$ The intensity of these peaks increased with the PVIIL content, suggesting that the PVIIL was successfully introduced to the Br-PES-Br chain during the membrane formation. The broad peak around $3476 \mathrm{~cm}^{-1}$ for the membranes is assigned to the stretching vibration of $-\mathrm{OH}$.

Menshutkin reaction occurred when Br-PES-Br was mixed with PVIIL at $60{ }^{\circ} \mathrm{C}$, forming the $\mathrm{Br}^{-}$-form PES/PVIIL- $x$ membranes. The $\mathrm{Br}^{-}$-form membranes are then immersed in a $\mathrm{KOH}$ solution to exchange $\mathrm{Br}^{-}$with $\mathrm{OH}^{-}$, thus producing the $\mathrm{OH}^{-}$-form PES/PVIIL- $x$. The EDS spectra of the $\mathrm{Br}^{-}$-form PES/ PVIIL-0.4 and $\mathrm{OH}^{-}$-form PES/PVIIL-0.4 were recorded to compare their core elemental composition. It can be observed in Fig. 2 that the sharp peak of bromine in $\mathrm{Br}^{-}$-form PES/PVIIL-
0.4 (Fig. 2a) declined and almost disappeared in the $\mathrm{OH}^{-}$-form PES/PVIIL-0.4 (Fig. 2b).

Furthermore, the membranes are insoluble in most of the commonly used organic solvents including dimethylformamide (DMF), dimethyl sulfoxide (DMSO), tetrahydrofuran (THF), chloroform $\left(\mathrm{CHCl}_{3}\right)$ and methanol at RT. This suggests the effective crosslinking within the membranes and vindicates the grafting of the Br-PES-Br chain onto the PVIIL backbone via crosslinking. This is also supported by the gel fractions $(>87 \%)$ in DMSO shown in Table 1.

\section{Morphology of the PES/PVIIL- $x$ membranes}

A representative morphology of the as-synthesized membranes is shown in Fig. 3. The membrane is transparent and flexible (Fig. 3a), which is a direct indicative of their good mechanical robustness for application in fuel cells. The microstructure of the AEMs reveals that both the membrane surface (Fig. 3b) and cross-section (Fig. 3c) are dense without pores. Meanwhile, the thickness of the as-synthesized membrane was estimated to be around $40 \mu \mathrm{m}$ (Fig. 3c). A thin (tens of micrometer) AEM tends to reduce the ohmic loss in cell voltage and thus promotes the power density of the PEMFCs. ${ }^{13}$

The surface topography of the AEMs was studied by AFM, as shown in Fig. 4. The darker regions are attributed to the soft hydrophilic domains while the brighter ones correspond to the hard hydrophobic domains. ${ }^{46}$ Distinct phase separation is seen in all of the membranes, and suggests the excellent structural design of AEMs adopted in this work as illustrated in Scheme 1.

The hydrophobic Br-PES-Br chain is immiscible with the hydrophilic PVIIL backbone, the domains containing imidazolium cations gather together and self-assemble to form the hydrophilic ionic clusters. By increasing the ratio of PVIIL to PES (PES/PVIIL-0.4), the interconnectivity of hydroxide domains become more pronounced because the size of the hydrophilic domains increased with the amount of imidazolium cations introduced into the polymer backbone, resulting in the more prominent ionic nanochannels. These hydrophilic nanochannels are highly favourable for the conduction of hydroxide ions.

SAXS was further employed to investigate the microphase separation of the AEMs. As shown in Fig. 5, the PES/PVIIL-0.4
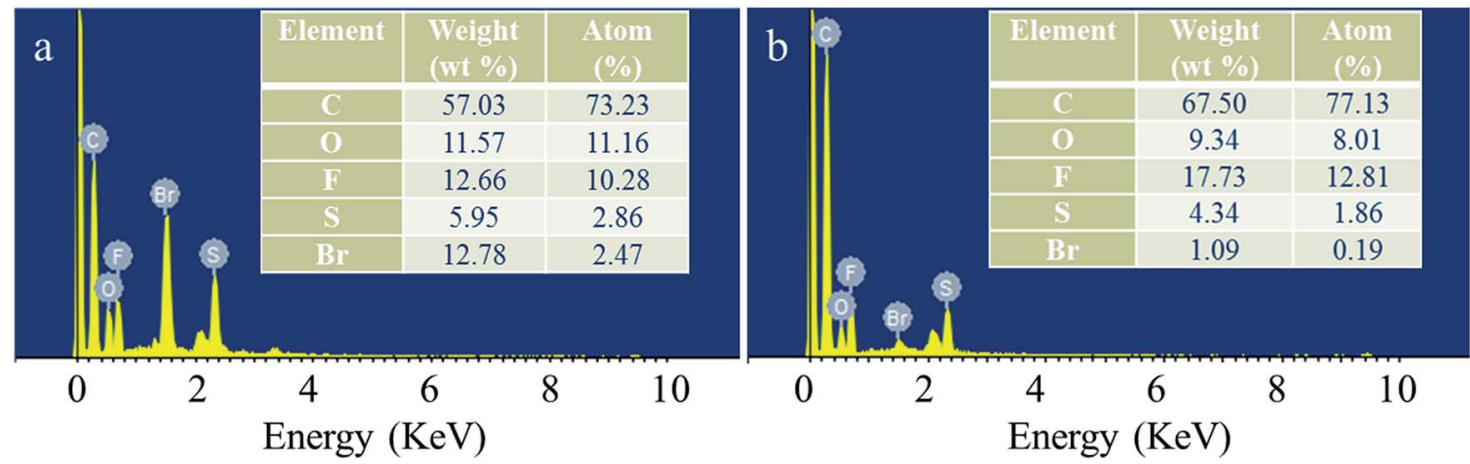

Fig. 2 EDS spectra of the (a) $\mathrm{Br}^{-}$-form PES/PVIIL-0.4 and (b) $\mathrm{OH}^{-}$-form PES/PVIIL-0.4 membranes. 
Table 1 The IEC, WU and SR of the crosslinked PES/PVIIL- $x$ membranes

\begin{tabular}{|c|c|c|c|c|c|c|c|c|}
\hline \multirow[b]{2}{*}{ PES/PVIIL- $x$} & \multirow[b]{2}{*}{$\mathrm{DC}^{a}(\%)$} & \multicolumn{2}{|c|}{$\operatorname{IEC}\left(\mathrm{meq} \mathrm{g}^{-1}\right)$} & \multicolumn{2}{|c|}{ Water uptake (\%) } & \multicolumn{2}{|c|}{ Swelling ratio (\%) } & \multirow[b]{2}{*}{ Gel fraction $(\%)$} \\
\hline & & $\mathrm{Cal}^{a}{ }^{a}$ & Exp. $^{b}$ & $30{ }^{\circ} \mathrm{C}$ & $60{ }^{\circ} \mathrm{C}$ & $30{ }^{\circ} \mathrm{C}$ & $60{ }^{\circ} \mathrm{C}$ & \\
\hline 0.5 & 6.2 & 2.21 & 1.34 & $16.29 \pm 0.17$ & $19.96 \pm 0.19$ & $7.14 \pm 0.12$ & $11.47 \pm 0.11$ & $91 \%$ \\
\hline 0.4 & 4.2 & 2.59 & 1.67 & $23.54 \pm 0.15$ & $28.37 \pm 0.20$ & $9.23 \pm 0.15$ & $15.44 \pm 0.13$ & $87 \%$ \\
\hline
\end{tabular}

${ }^{a}$ Calculated from the feeding monomer ratios. ${ }^{b}$ Experimental value determined by titration.

membrane with more dense ionic groups tends to display more profound scattering peak, which suggests larger spacing of ion conducting channels. ${ }^{47-49}$ The wide scattering peak at $0.42 \mathrm{~nm}^{-1}$ for the PES/PVIIL-0.4 membrane corresponds to the average interdomain spacing, $d$ of $14.9 \mathrm{~nm}$ (Bragg equation $(d=2 \pi / q)$ ). In contrast, there are no observable peaks for the PES/PVIIL0.67 membrane, probably due to the tiny interdomain spacing. This increased Bragg spacing with increased ratio of PVIIL to Br-PES-Br is consistent with the results of AFM.

\section{Properties of the PES/PVIIL- $x$ membranes}

Ionic exchange capacity (IEC), water uptake (WU), swelling ratio (SR). IEC is an important parameter that signifies the density of functional groups in a membrane and has a direct effect on the swelling ratio and water uptake of the membrane. In this study, the membranes with different IECs were designed by varying the crosslinking degree. The theoretical IEC of the membranes was calculated from the feeding monomer ratios with the assumption of complete reactions. As shown in Table 1, by increasing the weight ratio of PVIIL to Br-PES-Br, the IEC, water uptake and swelling ratio of the membranes increased. This suggests that the number of available ionic groups increased, but the degree of crosslinking (DC) decreased. The theoretical IECs range from 1.53 to $2.59 \mathrm{meq} \mathrm{g}^{-1}$ whereas the experimental values measured by back-titration range from 0.73 to $1.67 \mathrm{meq}^{-1}$. The titrated IECs were lower than the theoretical values probably because the quaternization degree of the PVIIL as calculated from the NMR spectra $(68 \%)$ is lower than the theoretical one.

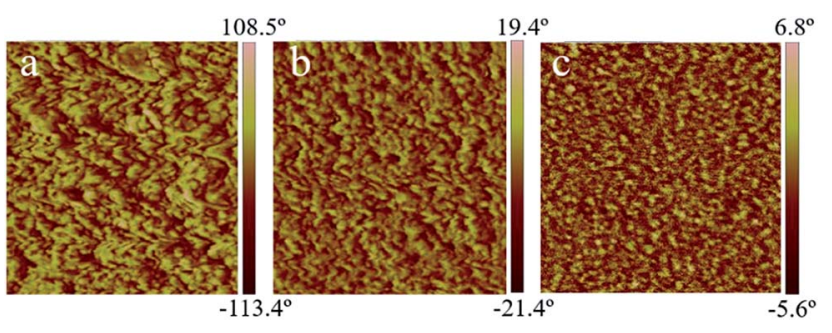

Fig. 4 AFM phase image of (a) PES/PVIIL-0.67 (b) PES/PVIIL-0.5 and (c) PES/PVIIL-0.4 membranes. Scale: $500 \times 500 \mathrm{~nm}$.

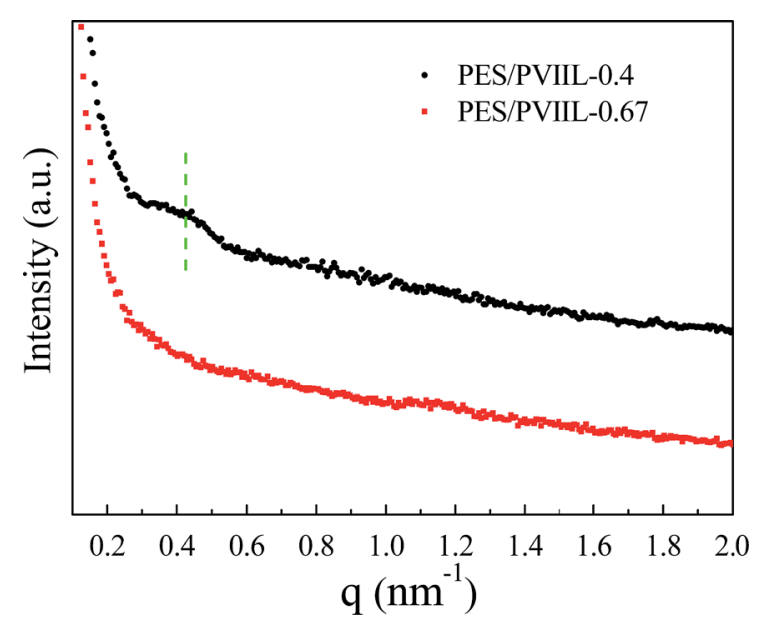

Fig. 5 SAXS profiles of the PES/PVIIL-x membranes.
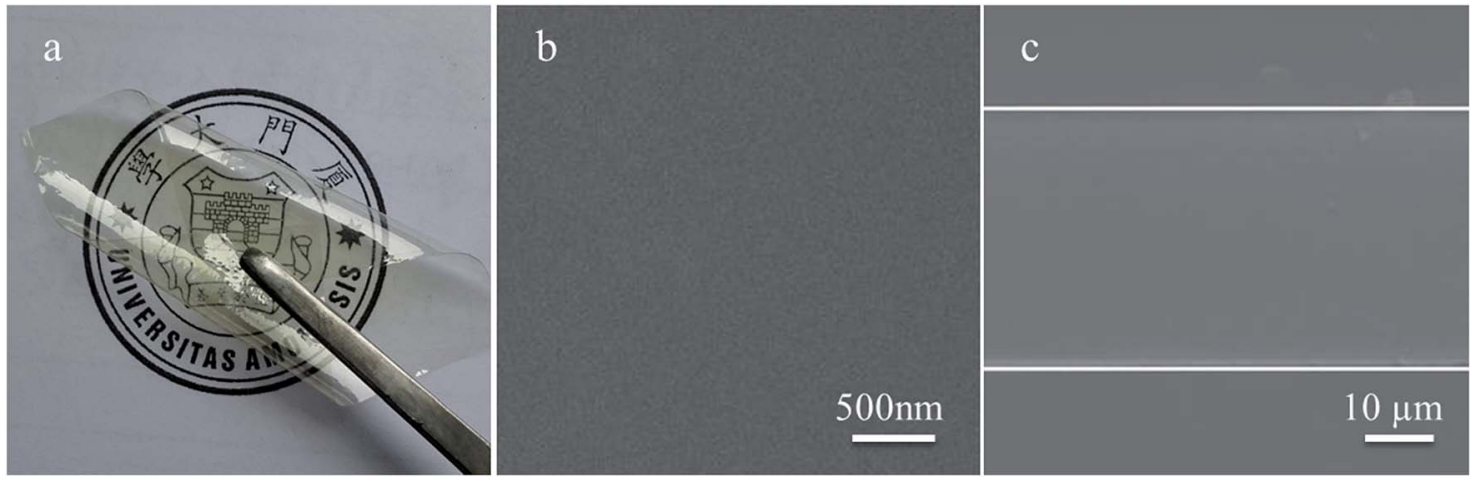

Fig. 3 Images of the PES/PVIIL-0.4 membrane: (a) digital photo, SEM image of (b) surface and (c) cross-section. 
Moderate amount of water molecules is beneficial to facilitate the hydroxide conductivity of the membranes while excess water could result in poor mechanical properties. ${ }^{50}$ Fig. 6a shows the water uptake and contact angle of the crosslinked membranes. The water uptake of the membranes expectedly increases with increasing IEC as well as with temperature. This is because the membranes with higher IEC exhibit higher affinity to water and higher mobility of water molecules. Polymer chains at higher temperature tend to create larger free volume. Meanwhile, PES/PVIIL- $x$ membranes displayed a lower water uptake in the range of $4.12-23.54 \%$ than the conventional imidazolium-based AEMs. ${ }^{5,51,52}$ This is because the strong hydrophobicity of poly(ether sulfone)s chain as well as the dense crosslinked structure simultaneously limits the excessive water uptake conducing to fewer water molecules absorbed in the membranes. In addition, the contact angle of the AEMs decreases from $94.39^{\circ}$ to $67.55^{\circ}$ with increasing the IEC. This suggests that the hydrophilicity of the AEMs increased with increasing the number of ionic groups.

The swelling ratio of the PES/PVIIL- $x$ membranes is shown in Fig. 6b. Notably, the relationship between SR and IEC/ temperature agrees well with that between water uptake and IEC/temperature. This is because higher water uptake always results in larger dimensional changes in the membrane. Compared with PES/PVIIL-0.67 and PES/PVIIL-0.5, the PES/ PVIIL-0.4 membrane has the highest swelling ratio of $9.23 \%$ at $30{ }^{\circ} \mathrm{C}$ and $15.44 \%$ at $60{ }^{\circ} \mathrm{C}$. Nevertheless, this value is much lower than that for Nafion-117 under the same testing condition (Fig. 6b). This is probably due to the crosslinked network formed within the membranes that effectively restricts the mobility of polymer chains, thus resulting in high dimensional stability.

Ionic conductivity. The hydroxide conductivity is of paramount importance for the application of AEMs in fuel cells. In general, the hydroxide conductivity is greatly influenced by IEC and water uptake with the value required to be above $10 \mathrm{mS}$ $\mathrm{cm}^{-1} .^{20}$ Fig. 7a shows the hydroxide conductivity of the PES/ PVIIL- $x$ membranes as a function of temperature. Obviously, the hydroxide conductivity of the three series of membranes increases with temperature because ion mobility and free volume increase with increasing temperature..$^{53}$ From PES/ PVIIL-0.67 to PES/PVIIL-0.4, the IEC increases from 0.73 to $1.67 \mathrm{meq}^{-1}$ (Table 1), while the hydroxide conductivity accordingly increases from 21.3 to $50.2 \mathrm{mS} \mathrm{cm}^{-1}$ at $60{ }^{\circ} \mathrm{C}$. Notably, the membrane with larger IEC has higher hydroxide conductivity. Particularly, the conductivity of the PES/PVIIL-0.4 membrane $\left(78.5 \mathrm{mS} \mathrm{cm}^{-1}, 80{ }^{\circ} \mathrm{C}\right)$ is much higher than that of the crosslinked HMTA/PVBC- $x: y$ membranes with comparable IEC. ${ }^{54}$ Moreover, the high conductivity of the PES/PVIIL-0.4 membrane is accompanied by a lower swelling ratio than the uncrosslinked AEMs with similar conductivity. ${ }^{4,51}$ This is probably because the hydrophilic/hydrophobic microphase separation morphology formed within the membrane efficiently promotes the hydroxide transport as confirmed by AFM. The crosslinked membranes with more compact network structure were expected to display higher mechanical stability.

Furthermore, the temperature dependence of conductivity is observed to be in good conformity with Arrhenius law, as shown in Fig. 7b. The estimated transport activation energy of $\mathrm{OH}^{-}$in the membranes follows the Arrhenius relation: $E_{\mathrm{a}}=-b R$, where $R$ is the universal gas constant $\left(R=8.314 \mathrm{~J} \mathrm{~mol}^{-1} \mathrm{~K}^{-1}\right)$, and $b$ is the slope of the Arrhenius plot, in the range of 19.38-23.40 kJ $\mathrm{mol}^{-1}$. The membranes with higher IEC have lower $E_{\mathrm{a}}$. This is because more ionic groups tend to absorb more water molecules and form more developed nanochannels inside the membrane, and thus facilitating the transport of hydroxide. ${ }^{51}$

Thermal stability and mechanical properties. The short-term thermal stability of the PES/PVIIL- $x$ membranes was examined by thermogravimetric analysis (TGA), as shown in Fig. 8. Clearly, three degradation steps were observed for the crosslinked membranes. The slight mass loss below $120{ }^{\circ} \mathrm{C}$ is due to the evaporation of residual water in the membranes. The second degradation step from about 180 to $300{ }^{\circ} \mathrm{C}$ is related to the decomposition of the imidazolium groups. The PES/PVIIL-0.4 membrane with the most imidazolium groups has the largest loss in weight. The degradation step above $300{ }^{\circ} \mathrm{C}$ is believed to be caused by the degradation of the copolymer main chain. Although the degradation temperature is depressed with
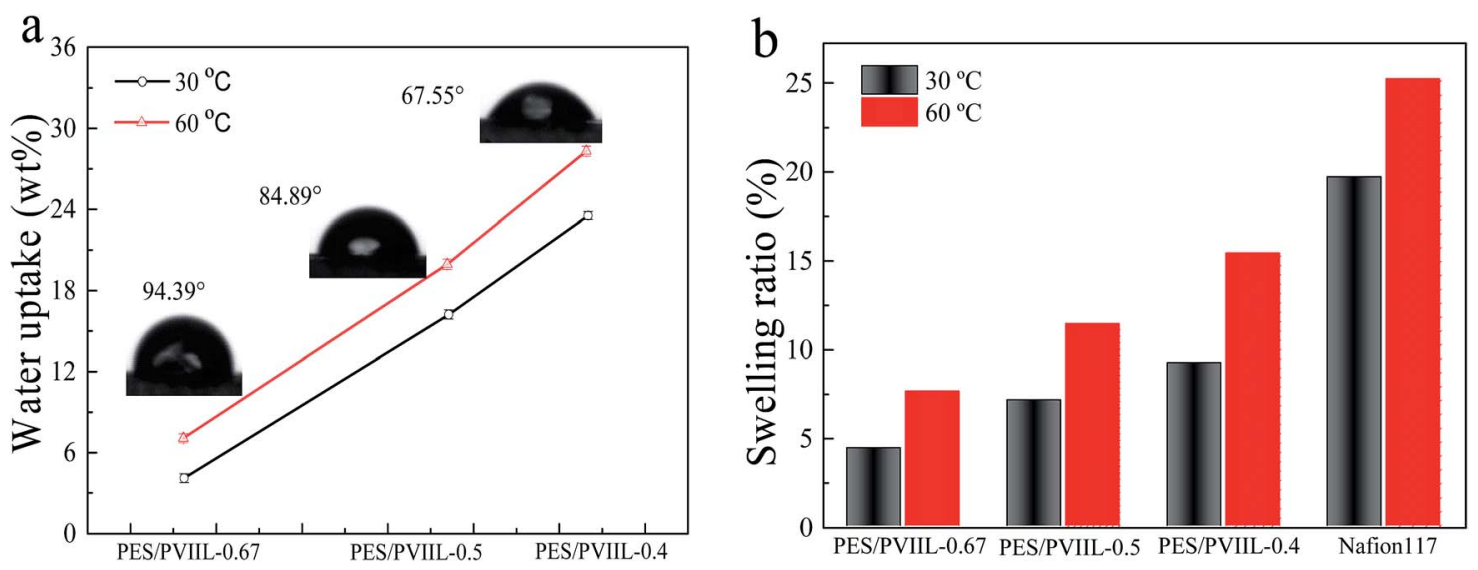

Fig. 6 (a) Water uptake and static water contact angle of the crosslinked PES/PVIIL- $x$ membranes, (b) SR of the crosslinked PES/PVIIL- $x$ membranes and Nafion® 117. 
a

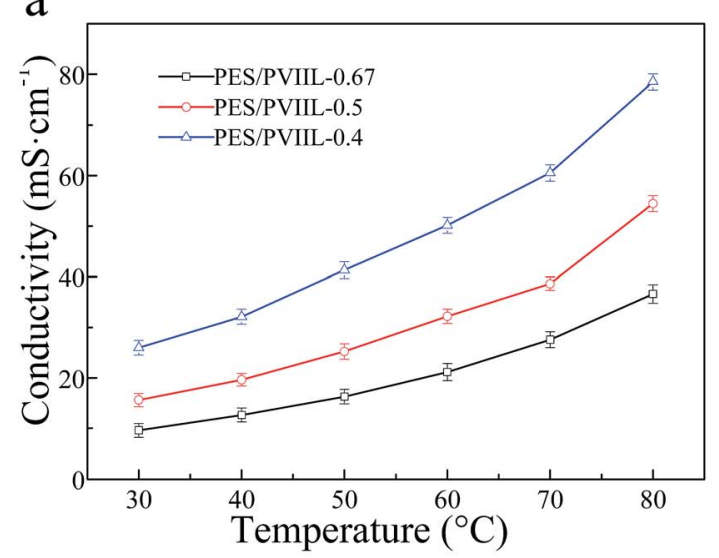

b

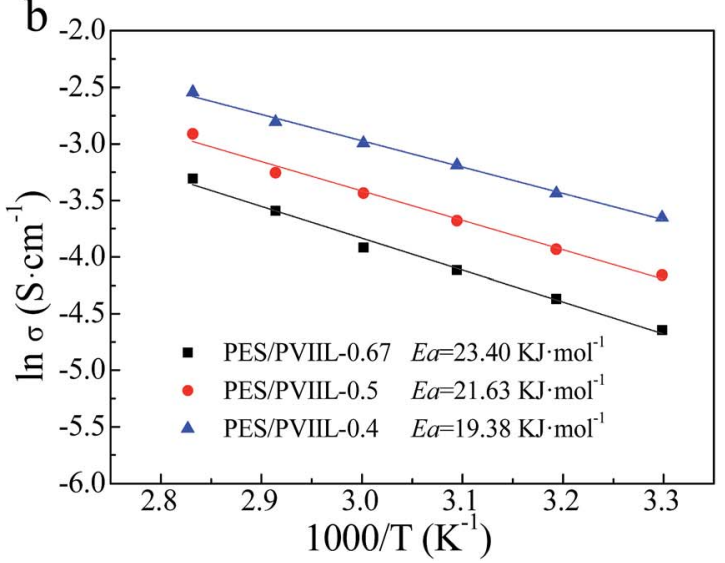

Fig. 7 (a) Temperature dependence of the ionic conductivity and (b) In $\sigma-1 / T$ plot of the crosslinked membranes (PES/PVIIL-x).

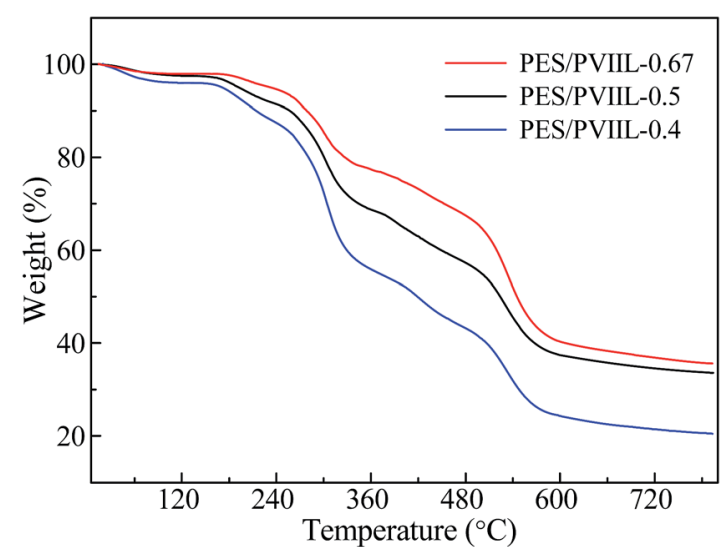

Fig. 8 TGA curves of the AEMs under a nitrogen atmosphere.

increasing feeding weight ratio of PVIIL to Br-PES-Br, all the membranes are thermally stable below $180^{\circ} \mathrm{C}$. Moreover, time dependent remaining weight of the PES/PVIIL-0.4 membrane at $120^{\circ} \mathrm{C}$ was conducted for better understanding of the long-term thermal stability of the AEMs. It can be observed from Fig. S4 $\uparrow$ that the PES/PVIIL-0.4 membrane can maintain a constant weight at $120^{\circ} \mathrm{C}$ for up to $50 \mathrm{~h}$. This suggests the good thermal stability of the PES/PVIIL- $x$ membranes for practical application.

Sufficient mechanical strength is another essential property for AEMs to meet the requirement for hot-press and long-term application. Table 2 shows the mechanical properties of the as-synthesized PES/PVIIL- $x$ membranes at RT. By increasing the
IEC, the tensile strength of the membranes decreases from 32.9 to $21.2 \mathrm{MPa}$, the Young's modulus decreases from 509 to $197 \mathrm{MPa}$ and the elongation at break increases from $14.5 \%$ to $33.8 \%$. The reduced tensile strength and the improved elongation at break of the crosslinked membranes could be attributed to the abundant ionic groups that induce higher water uptake and the absorbed water acts as a plasticizer, ${ }^{52}$ thus weakening the mechanical properties.

Alkaline stability. The alkaline stability of AEMs is considered to be another important property for AEMFCs. The AEMs with long-term alkaline stability will maintain a relatively high conductivity and good mechanical property after treating with high-concentrated alkali for a long time. Nonetheless, the change in the conductivity and IEC of the PES/PVIIL-0.4 membrane during the alkaline stability test in a $2 \mathrm{M} \mathrm{KOH}$ solution at $60^{\circ} \mathrm{C}$, shown in Fig. 9, gives a better evaluation of the alkaline stability of the AEMs. The conductivity reduced drastically during the initial $150 \mathrm{~h}$. After which, the conductivity had a negligible change and maintained around $65 \%$ of the initial value. The IEC decreased from 1.67 to $1.12 \mathrm{meq}^{-1}$ after $650 \mathrm{~h}$ of immersion in high $\mathrm{pH}$ solutions. The decrease of IEC is consistent with the tendency of conductivity and therefore justifies the moderate alkaline stability of the AEMs in this work.

Furthermore, the FT-IR spectra of the membranes after exposure to the alkaline environment for 30 days are shown in Fig. S5. $\uparrow$ The membranes maintain a considerable stability in alkaline media considering only tiny change in the intensity of the imidazolium groups.

Table 2 Mechanical properties of the crosslinked PES/PVIIL-x membranes before and after alkaline test

\begin{tabular}{|c|c|c|c|c|c|c|}
\hline \multirow[b]{2}{*}{ Membranes } & \multicolumn{2}{|c|}{ Tensile strength (MPa) } & \multicolumn{2}{|c|}{ Young's modulus (MPa) } & \multicolumn{2}{|c|}{ Elongation at break (\%) } \\
\hline & Before & After & Before & After & Before & After \\
\hline PES/PVIIL-0.5 & $28.4 \pm 1.3$ & $22.6 \pm 1.5$ & $321 \pm 18$ & $288 \pm 15$ & $26.7 \pm 1.8$ & $21.3 \pm 1.5$ \\
\hline PES/PVIIL-0.4 & $21.2 \pm 0.9$ & $17.3 \pm 0.8$ & $197 \pm 12$ & $162 \pm 11$ & $33.8 \pm 2.1$ & $29.6 \pm 1.9$ \\
\hline
\end{tabular}




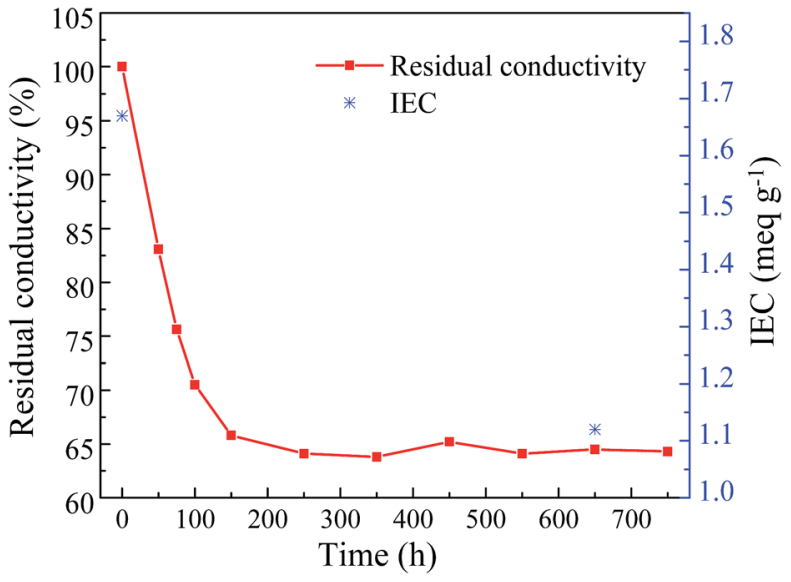

Fig. 9 Time dependent residual conductivity and IEC of the PES/ PVIIL-0.4 membrane in a $2 \mathrm{M} \mathrm{KOH}$ solution at $60^{\circ} \mathrm{C}$.

The changes in mechanical properties of the PES/PVIIL-0.4 membranes after 30 days' alkaline stability test (Table 2) reveal $18 \%$ loss in tensile strength for the PES/PVIIL-0.4 membrane. This is due to the destruction of crosslinked network when imidazolium groups were degraded. Nonetheless, the conductivity and mechanical property after the alkali accelerated test still maintain a moderate level, suggesting a reasonable alkaline-resistance for long-term application. Especially, the PES/PVIIL-0.4 membrane displayed higher alkaline resistance than the quaternary ammonium based AEMs. ${ }^{55-57}$ This is possibly due to the following reasons: (1) the presence of the $\pi$-conjugated imidazole ring reduced the $\mathrm{S}_{\mathrm{N}} 2$ substitution reactions thus improved the chemical stability of the imidazolium cations. ${ }^{3}$ (2) The effective crosslinked network in this study probably protects the membranes from hydroxide ions attack, which is consistent with the results on conductivity and mechanical property.

Fabrication of MEA and fuel cell performance. The $\mathrm{OH}^{-}$form PES/PVIIL-0.4 membrane was chosen for the fabrication of MEA and fuel cell performance test due to its high conductivity,

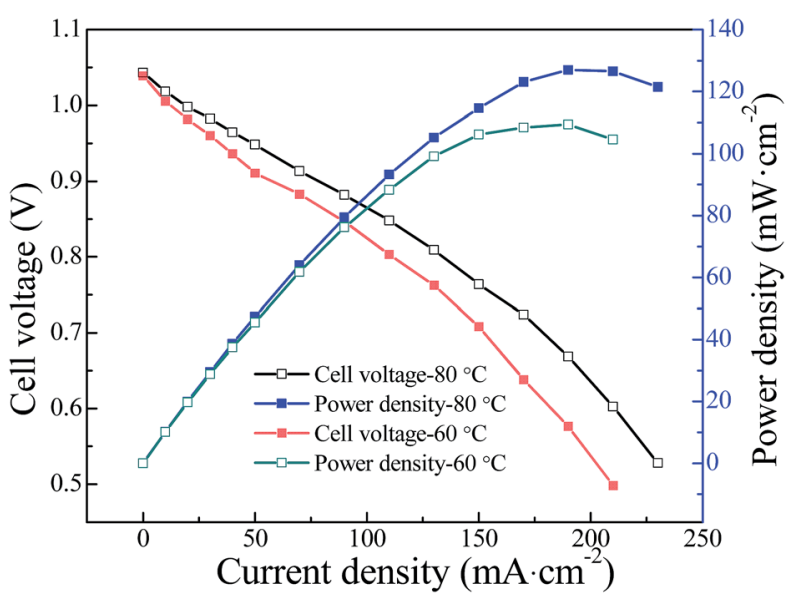

Fig. 10 Polarization curve of $\mathrm{H}_{2} / \mathrm{O}_{2}$ fuel cell using PES/PVIIL-0.4 membrane at $60^{\circ} \mathrm{C}$ and $80^{\circ} \mathrm{C}$. good dimensional stability and sufficient alkaline-resistance. Fig. 10 shows the dependence of cell voltage and power density on the current density of the MEA at 60 and $80^{\circ} \mathrm{C}$. The $I /$ $V$ data were collected after conditioning for $5 \mathrm{~h}$ at $10 \mathrm{~mA}$ and the obtained data were plotted every $5 \mathrm{~min}$. The open circuit voltage $(\mathrm{OCV})$ is $1.039 \mathrm{~V}$, and is close to the theoretical value of $1.23 \mathrm{~V} .^{58}$ With the increment of current density, the power density gradually increased and achieved the peak value of $109.5 \mathrm{~mW}$ $\mathrm{cm}^{-2}$ at the current density of $190 \mathrm{~mA} \mathrm{~cm}{ }^{-2}$ at $60{ }^{\circ} \mathrm{C}$. This is much higher than that using BPPO-based membrane $(42.5 \mathrm{~mW}$ $\mathrm{cm}^{-2}, 60{ }^{\circ} \mathrm{C}$ ) prepared via thermal-crosslinking ${ }^{59}$ and QPMVPDVB $10 \%$ membrane $\left(80 \mathrm{~mW} \mathrm{~cm}^{-2}, 70{ }^{\circ} \mathrm{C}\right)$ synthesized by sIPN crosslinking. ${ }^{60}$ Moreover, the power density increased with the temperature and the maximum power density at $80{ }^{\circ} \mathrm{C}$

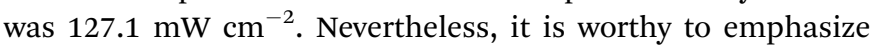
that not only does the inherent property of the AEMs but also the content of catalyst, MEA fabrication method and the practical operating condition influence the performance of fuel cells.

The current work especially focused on the novel synthesis method, properties of the AEMs and the single-cell performance without optimization. For a better single cell performance, the MEA fabrication method and testing condition are underway in our lab.

\section{Conclusions}

We have synthesized a series of novel macrocrosslinked imidazolium-based AEMs by crosslinking poly(vinyl imidazole) ionic liquid with bromide-terminated poly(ether sulfone) via Menshutkin reaction. The as-synthesized PES/PVIIL- $x$ membranes demonstrated low water uptake and enhanced dimensional stability due to the formation of crosslinked network structure. The incompatibility of the hydrophilic imidazolium cations from the functionalized poly(vinyl imidazole) with the long hydrophobic poly(ether sulfone) chain promoted the hydrophilic/hydrophobic phase separation. Notably, the PES/PVIIL-0.4 membrane with the IEC of $1.67 \mathrm{meq}^{-1}$ displayed the highest hydroxide conductivity of $78.5 \mathrm{mS} \mathrm{cm}^{-1}$ at $80{ }^{\circ} \mathrm{C}$. All of the PES/PVIIL- $x$ membranes exhibited good thermal stability and robust mechanical properties that meet the requirements for applications in alkaline fuel cells. Moreover, the PES/PVIIL-0.4 membrane can maintain $65 \%$ conductivity and $82 \%$ tensile strength after immersing in a $2 \mathrm{M} \mathrm{KOH}$ solution at $60{ }^{\circ} \mathrm{C}$ for 30 days. The high performances of PES/ PVIIL-0.4 membrane demonstrates its potentiality for fuel cell application.

\section{Acknowledgements}

Financial support from the National Nature Science Foundation of China (grant no. 21376194 \& 21576226), and the research fund for the Priority Areas of Development in Doctoral Program of Higher Education (no. 20130121130006) is gratefully acknowledged. 


\section{Notes and references}

1 M. D. T. Nguyen, S. Yang and D. Kim, J. Power Sources, 2016, 328, 355-363.

2 H. Y. Yao, N. N. Song, K. X. Shi, S. N. Feng, S. Y. Zhu, Y. H. Zhang and S. W. Guan, Polym. Chem., 2016, 7, 47284735.

3 B. C. Lin, H. L. Dong, Y. Y. Li, Z. H. Si, F. L. Gu and F. Yan, Chem. Mater., 2013, 25, 1858-1867.

4 G. Das, B. J. Parkb and H. H. Yoon, J. Mater. Chem. A, 2016, 4, 15554-15564.

5 W. Li, J. Fang, M. Lv, C. X. Chen, X. J. Chi, Y. X. Yang and Y. M. Zhang, J. Mater. Chem., 2011, 21, 11340-11346.

6 A. K. Sahu, K. Ketpang, S. Shanmugam, O. Kwon, S. Lee and H. Kim, J. Phys. Chem. C, 2016, 120, 15855-15866.

7 Y. H. Yin, Z. Li, X. Yang, L. Cao, C. B. Wang, B. Zhang, H. Wu and Z. Y. Jiang, J. Power Sources, 2016, 332, 265-273.

8 B. C. Lin, F. Q. Chu, Y. R. Ren, B. P. Jia, N. Y. Yuan, H. Shang, T. Y. Feng, Y. Y. Zhu and J. N. Ding, J. Power Sources, 2014, 266, 186-192.

9 L. S. Wang, A. N. Lai, C. X. Lin, Q. G. Zhang, A. M. Zhu and Q. L. Liu, J. Membr. Sci., 2015, 492, 58-66.

10 H. S. Dang and P. Jannasch, Macromolecules, 2015, 48, 57425751.

11 M. Zhang, J. L. Liu, Y. G. Wang, L. N. An, M. D. Guiver and N. W. Li, J. Mater. Chem. A, 2015, 3, 12284-12296.

12 Z. J. Yang, J. Q. Hou, X. Y. Wang, L. Wu and T. W. Xu, Macromol. Rapid Commun., 2015, 36, 1362-1367.

13 N. W. Li, Q. Zhang, C. Y. Wang, Y. M. Lee and M. D. Guiver, Macromolecules, 2012, 45, 2411-2419.

14 H. Ono, J. Miyake, S. Shimada, M. Uchida and K. Miyatake, J. Mater. Chem. A, 2015, 3, 21779-21788.

15 M. Iravaninia and S. Rowshanzamir, Fuel Cells, 2016, 16, 135-149.

16 X. M. Wu, W. T. Chen, X. M. Yan, G. H. He, J. J. Wang, Y. Zhang and X. P. Zhu, J. Mater. Chem. A, 2014, 2, 1222212231.

17 W. T. Chen, X. M. Yan, X. M. Wu, S. Q. Huang, Y. L. Luo, X. Gong and G. H. He, J. Membr. Sci., 2016, 514, 613-621.

18 Q. Li, L. Liu, Q. Q. Miao, B. K. Jin and R. Bai, Chem. Commun., 2014, 50, 2791-2793.

19 E. A. Weiber and P. Jannasch, J. Membr. Sci., 2016, 520, 425433.

20 J. R. Varcoe, P. Atanassov, D. R. Dekel, A. M. Herring, M. A. Hickner, P. A. Kohl, A. R. Kucernak, W. E. Mustain, K. Nijmeijer, K. Scott, T. W. Xu and L. Zhuang, Energy Environ. Sci., 2014, 7, 3135-3191.

21 J. Pan, C. Chen, Y. Li, L. Wang, L. S. Tan, G. W. Li, X. Tang, L. Xiao, J. T. Lu and L. Zhuang, Energy Environ. Sci., 2014, 7, 354-360.

22 C. H. Hsu and C. C. Wan, J. Power Sources, 2003, 115, 268273.

23 S. Y. Lee, N. R. Kang, D. W. Shin, C. H. Lee, K. S. Lee, M. D. Guiver, N. W. Li and Y. M. Lee, Energy Environ. Sci., 2012, 5, 9795-9802.
24 K. H. Lee, D. H. Cho, Y. M. Kim, S. J. Moon, J. G. Seong, D. W. Shin, J. Y. Sohn, J. F. Kima and Y. M. Lee, Energy Environ. Sci., 2017, 10, 275-285.

25 G. H. Nie, X. H. Li, J. X. Tao, W. J. Wu and S. J. Liao, J. Membr. Sci., 2015, 474, 187-195.

26 J. Ran, L. Wu, Q. Q. Ge, Y. Y. Chen and T. W. Xu, J. Membr. Sci., 2014, 470, 229-236.

27 D. Guo, Y. Z. Zhuo, A. N. Lai, Q. G. Zhang, A. M. Zhu and Q. L. Liu, J. Membr. Sci., 2016, 518, 295-304.

28 A. H. N. Rao, S. Y. Namb and T. H. Kim, Int. J. Hydrogen Energy, 2014, 39, 5919-5930.

29 Y. Z. Zhuo, A. N. Lai, Q. G. Zhang, A. M. Zhu, M. L. Ye and Q. L. Liu, J. Membr. Sci., 2015, 491, 138-148.

30 S. Vengatesan, S. Santhi, G. Sozhan, S. Ravichandran, D. J. Davidson and S. Vasudevan, RSC Adv., 2015, 5, 2736527371.

31 J. J. Wang, G. H. He, X. M. Wu, X. M. Yan, Y. P. Zhang, Y. D. Wang and L. Du, J. Membr. Sci., 2014, 459, 86-95.

32 C. X. Lin, X. L. Huang, D. Guo, Q. G. Zhang, A. M. Zhu, M. L. Ye and Q. L. Liu, J. Mater. Chem. A, 2016, 4, 1393813948.

33 N. W. Li, Y. J. Leng, M. A. Hickner and C. Y. Wang, J. Am. Chem. Soc., 2013, 135, 10124-10133.

34 X. Dong, S. H. Hou, H. C. Maoa, J. F. Zheng and S. B. Zhang, J. Membr. Sci., 2016, 518, 31-39.

35 X. H. Li, Q. F. Liu, Y. F. Yu and Y. Z. Meng, J. Membr. Sci., 2014, 467, 1-12.

36 Y. B. He, J. J. Si, L. Wu, S. L. Chen, Y. Zhu, J. F. Pan, X. L. Ge, Z. J. Yang and T. W. Xu, J. Membr. Sci., 2016, 515, 189-195.

37 B. C. Lin, L. H. Qiu, J. M. Lu and F. Yan, Chem. Mater., 2010, 22, 6718-6725.

38 M. L. Guo, J. Fang, H. K. Xu, W. Li, X. H. Lu, C. H. Lan and K. Y. Li, J. Membr. Sci., 2010, 362, 97-104.

39 A. N. Lai, K. Zhou, Y. Z. Zhuo, Q. G. Zhang, A. M. Zhu, M. L. Ye and Q. L. Liu, J. Membr. Sci., 2016, 497, 99-107.

40 A. Jasti and V. K. Shahi, J. Power Sources, 2014, 267, 714-722.

41 K. Emmanuel, C. L. Cheng, B. Erigene, A. N. Mondal, M. M. Hossain, M. I. Khan, N. UlAfsar, G. Liang, L. Wu and T. W. Xu, J. Membr. Sci., 2016, 497, 209-215.

42 B. Qiu, B. C. Lin, Z. H. Si, L. H. Qiu, F. Q. Chu, J. Zhao and F. Yan, J. Power Sources, 2012, 217, 329-335.

43 P. Y. Xu, K. Zhou, G. L. Han, Q. G. Zhang, A. M. Zhu and Q. L. Liu, J. Membr. Sci., 2014, 457, 29-38.

44 J. C. Moore and J. G. Hendrickson, J. Polym. Sci., Part C: Polym. Symp., 1965, 8, 233-241.

45 A. N. Lai, L. S. Wang, C. X. Lin, Y. Z. Zhuo, Q. G. Zhang, A. M. Zhu and Q. L. Liu, J. Membr. Sci., 2015, 481, 9-18.

46 J. Pan, Y. Li, J. J. Han, G. W. Li, L. S. Tan, C. Chen, J. T. Lu and L. Zhuang, Energy Environ. Sci., 2013, 6, 2912-2915.

47 W. Germer, J. Leppin, C. N. Kirchner, H. Cho, H. J. Kim, D. Henkensmeier, K. Y. Lee, M. Brela, A. Michalak and A. Dyck, Macromol. Mater. Eng., 2015, 300, 497-509.

48 L. Z. Wang and M. A. Hickner, Polym. Chem., 2014, 5, 29282935.

49 L. Z. Wang and M. A. Hickner, Soft Matter, 2016, 12, 53595371. 
50 M. A. Hossain, H. Jang, S. Lee, T. Hong, L. Jin, F. Tan, D. Kim and W. Kim, Int. J. Hydrogen Energy, 2015, 40, 1324-1332.

51 C. X. Lin, Y. Z. Zhuo, A. N. Lai, Q. G. Zhang, A. M. Zhu, M. L. Ye and Q. L. Liu, J. Membr. Sci., 2016, 513, 206-216.

52 A. N. Lai, L. S. Wang, C. X. Lin, Y. Z. Zhuo, Q. G. Zhang, A. M. Zhu and Q. L. Liu, ACS Appl. Mater. Interfaces, 2015, 7, 8284-8292.

53 L. Gao, G. H. He, Y. Pan, B. L. Zhao, X. W. Xu, Y. J. Liu, R. L. Deng and X. M. Yan, J. Membr. Sci., 2016, 518, 159-167.

54 S. Vengatesan, S. Santhi, G. Sozhan, S. Ravichandran, D. J. Davidson and S. Vasudevan, RSC Adv., 2015, 5, 2736527371.
55 T. Sata, M. Tsujimoto, T. Yamaguchi and K. Matsusaki, J. Membr. Sci., 1996, 112, 161-170.

56 S. Chempath, B. R. Einsla, L. R. Pratt, C. S. Macomber, J. M. Boncella, J. A. Rau and B. S. Pivovar, J. Phys. Chem. C, 2008, 112, 3179-3182.

57 C. S. Macomber, J. M. Boncella, B. S. Pivovar and J. A. Rau, J. Therm. Anal. Calorim., 2008, 93, 225-229.

58 H. W. Zhang, D. Z. Chen, Y. Xianze and S. B. Yin, Fuel Cells, 2015, 15, 761-780.

59 L. Wu, Q. Pan, J. R. Varcoe, D. Zhou, J. Ran, Z. J. Yang and T. W. Xu, J. Membr. Sci., 2015, 490, 1-8.

60 Y. T. Luo, J. C. Guo, C. S. Wang and D. Chu, Electrochem. Commun., 2012, 16, 65-68. 